\title{
Habituation and the occurrence of photically evoked afterdischarges in the albino rat
}

\author{
ERIN D. BIGLER and DONOVAN E. FLEMING \\ Brigham Young University, Provo, Utah 84602
}

\begin{abstract}
Photically evoked afterdischarge (AD) parameters were examined in albino rats during the time course of $1 \mathrm{~h}$ of iterative photic stimulation (515 light flashes). It was observed that percentage of AD elicitation, duration of $\mathrm{AD}$ activity, and number of spindle waves per $\mathrm{AD}$ increased and then subsequently decreased over time. The amplitude of the largest peak-to-peak wave per AD was unaffected by time. Greatest AD elicitation took place during the 5- to 15-min time segment following the initiation of iterative photic stimulation. Likewise, the last $5 \mathrm{~min}$ of iterative stimulation yielded the lowest AD elicitation scores. These data suggest the operations of an arousal continuum in the process of $\mathrm{AD}$ elicitation. It was also observed that spontaneous AD-like waves occurred in the visual cortex at irregular intervals that were not specifically correlated with the light flashes.
\end{abstract}

Incidental to observations regarding the circumstances under which photically evoked afterdischarge (AD) bursts could be elicited from the primary visual cortex of the albino rat, it has been reported that AD bursting occurred in a pattern which was somewhat at variance with the typical course of habituation. Whereas it had been expected that AD bursting would diminish over time (Hinde, 1970; Thompson \& Spencer, 1966), it was found that the frequency of bursting first increased to a maximum level, then decreased (Rhodes \& Fleming, 1970). Although these results have been replicated under different conditions (Fleming, Rhodes, Wilson, \& Shearer, 1972, 1973a; Fleming, Wilson, \& Shearer, $1973 \mathrm{~b}$ ), the sampling procedures were not designed to yield any definitive in-depth treatment of the time course of $\mathrm{AD}$ habituation. Thus, the present investigation was carried out to rectify the sampling inadequacies of the previous studies and to examine in detail AD burst parameters under the conditions of short-term habituation.

\section{METHOD}

A group of 13 Holtzman albino rats, 90-120 days of age at the start of the investigation, served as experimental Ss. The animals were individually housed and were kept on ad lib food and water.

The rats were anesthetized with pentobarbital sodium $(40 \mathrm{mg} / \mathrm{kg})$ and were surgically prepared with in-dwelling electrodes implanted over the right and left visual cortices at points $7 \mathrm{~mm}$ posterior to the bregma and $3 \mathrm{~mm}$ lateral to the midline. An electrode was placed in the frontal sinus for grounding. The reference electrode was placed in the calvarium overlying the cerebellum or the technique of Draper and Venator (1972) was adapted to provide for a reference electrode. The pin receptacles for the various electrodes were imbedd ed with dental acrylic plastic and the wound was closed. At least 7 days of recovery were allowed before any treatment sessions were initiated. All experimental procedures were carried out in waking animals with mydriatic pupils (1\% atropine sulfate).

A Grass Model PS22 photostimulator was used to deliver $10-\mu \mathrm{sec}$ light pulses to a reflecting hemicylinder. The hemicylinder was placed in front of a hammock in which an animal was held under light restraint. With the photostimulator lamp placed $42.5 \mathrm{~cm}$ behind and slightly above the hemicylinder and with the stimulator intensity setting at 2 on a 1-16 scale, the illuminance of the reflecting surface was approximately $5 \mathrm{fc}$. Brain responses were amplified with Grass 5P5 preamplifiers and Model 5 polygraph driver amplifiers (bandwidth, 0.3-60 Hz), and ink-written records were obtained.

The experiment was carried out in this manner: A rat was acclimated to the hammock for approximately $15 \mathrm{~min}$. Single photic pulses were then presented at a rate of $1 / 7 \mathrm{sec}$. The photic iteration was continued for a $1-\mathrm{h}$ period (515 photic presentations) while the ink record was examined for ADs. This procedure served as a screening index for the occurrence of $\mathrm{AD}$ bursting and was repeated at least twice for all animals. Those animals displaying consistent AD patterns constituted the sample of this investigation. Following the screening procedure, the rat was returned to the recording situation and the photic pulses were again presented at the rate of $1 / 7 \mathrm{sec}$ for $1 \mathrm{~h}$. For analysis the 1 -h period was broken into six 10-min segments. For each 10-min segment the following data were obtained: the percentage of AD bursts elicited, the number of waves/bursts, the peak-to-peak amplitudes of the largest wave component in the burst, and burst duration. These data for the six time segments were compared with analysis of variance techniques.

\section{RESULTS}

The data summarizing the effects of habituation and $\mathrm{AD}$ parameters are presented in Table 1. Figure 1 depicts the corresponding changes in $\mathrm{AD}$ parameters over the six sampling time periods.

With respect to the percentage of $\mathrm{AD}$ bursts occurring during the successive 10 -min sampling periods (Table 1 ), it was observed that there were reliable differences between the time sampling blocks $(F=6.52, \mathrm{df}=5 / 60$, $p<.01)$. Newman-Keuls tests indicated that AD percentage was significantly greater for Blocks 1,2, 3, and 4 when compared with Block 6 and that Block $2 \mathrm{AD}$ percentage was significantly greater than Block 5. Blocks 5 and 6 did not differ. The greatest percentage of bursting occurred during the second sampling period. It was determined that the first burst of $\mathrm{AD}$ was elicited on the average of $87 \mathrm{sec}$ following the onset of the photic iteration (a mean of 12.4 photic pulses). To test the stability of AD bursting, a criterion of four consecutive 
bursts was set and it was observed that, on the average, 4.25 min elapsed before this criterion was met (a mean of 36.6 photic pulse presentations). Because a mean of 4.25 min elapsed before the consecutive burst criterion was met, it was questioned whether the first 10-min sampling interval was an adequate index of the percentage of AD bursting for the early stages of photic iteration. Accordingly, the first, second, and sixth sampling blocks were divided into 5-min intervals for analysis of bursting percentage. These observations are also presented in Table 1. For the first $10-\mathrm{min}$ period, it was determined that the 0 - to 5 -min sample was considerably lower than the 5- to 10-min sample. On the other hand, the 5- to 10-min sample was of the same magnitude as the two 5-min values of the second 10-min block. Thus, it would appear that AD bursting reaches a maximum level during the second $5 \mathrm{~min}$ of photic iteration and declines thereafter. AD bursting percentage reached the lowest level during the second 5-min sample of the sixth 10-min period.

The number of waves per burst also yielded a reliable difference between sampling blocks $(\mathrm{F}=4.43, \mathrm{df}=5 / 60$, $\mathrm{p}<.01)$. The Newman-Keuls comparisons indicated that the difference between Blocks 2 and 6 was significant, i.e., there were fewer wave components during the sixth sampling block than during the second block (see Fig. 1). No other comparison was significant.

The peak-to-peak amplitude of the largest wave in the $\mathrm{AD}$ burst did not prove to be a reliable parameter $(F=3.06, \mathrm{df}=5 / 60, \mathrm{p}<.10)$ with respect to time sampling. However, the duration of the burst was a reliable indicator of habituation $(F=5.70, d f=5 / 60$, $\mathrm{p}<.01)$. Newman-Keuls tests indicated that burst duration was significantly greater during Blocks 1 and 2 than during Block 6 (see Fig. 1). In addition, Block 1 measures were also significantly greater than Block 5 measures. The remaining comparisons were not significant.

It was not uncommon to observe cortical bursts of high-amplitude waves resembling AD bursts occurring in the time interval between photic pulse presentations. On the average, a typical record would have 19 such bursts. In addition, on approximately 10 occasions, a burst of cortical discharges resembling an AD burst would occur just prior to and be in progress when the photic pulse was delivered. On a similar number of occasions (11) it

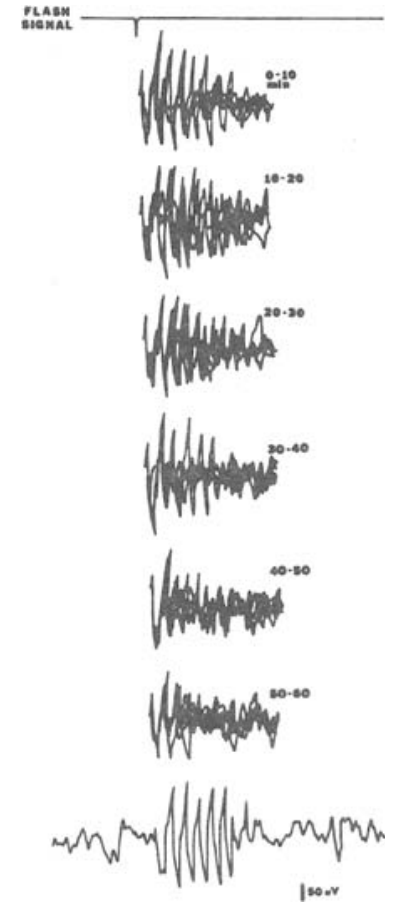

Fig. 1. EEG inscriptions of five superimposed photically evoked afterdischarges for each of the six sampling periods. Each inscription was taken at equal intervals. The bottom single inscription is a typical afterdischarge recorded in the 0 - to $10-\mathrm{min}$ segment. Note the depression of late occurring afteractivity as the $1-\mathrm{h}$ session progresses. Time interval is $1500 \mathrm{msec}$; upward deflection represents negativity.

was observed that an AD burst would not occur in association with the onset of the photic pulse but would occur between 0.5 and $2 \mathrm{sec}$ following the stimulus. These results are illustrated in Fig. 2.

\section{DISCUSSION}

In previous investigations it was observed that when $\mathrm{AD}$ bursting was sampled at the initiation $(0 \mathrm{~min}), 5$, and $15 \mathrm{~min}$ following the onset of photic iteration the greatest amount of bursting occurred in the 5-min sampling period (Fleming et al, 1972, 1973a, b; Rhodes \& Fleming, 1970). The 0-min sampling period was always significantly lower in terms of $\mathrm{AD}$ production than the 5-min sample. The 15 -min sample was consistently lower than the 5-min sample but not significantly so. There is a good deal of consistency between previous studies and the

Table 1

Mean ( \pm Standard Error of the Mean) Values of Afterdischarge Parameters Over Six Sampling Periods

\begin{tabular}{|c|c|c|c|c|c|c|c|c|c|}
\hline \multirow{2}{*}{$\begin{array}{c}\text { Afterdischarge } \\
\text { Parameter }\end{array}$} & \multicolumn{9}{|c|}{ Successive 10-Min Samples } \\
\hline & \multicolumn{2}{|c|}{1} & \multicolumn{2}{|c|}{2} & 3 & 4 & 5 & \multicolumn{2}{|c|}{6} \\
\hline \multirow{3}{*}{ AD Percentage } & $0-5$ & $5-10$ & $10-15$ & $15-20$ & & & & $50-55$ & $55-60$ \\
\hline & Min & Min & $\operatorname{Min}$ & Min & & & & Min & Min \\
\hline & $\begin{array}{r}40.2 \\
\pm 6.32\end{array}$ & $\begin{array}{r}57.9 \\
\pm 3.60\end{array}$ & $\begin{array}{r}56.5 \\
\pm 4.96\end{array}$ & $\begin{array}{r}53.3 \\
\pm 4.73\end{array}$ & & & & $\begin{array}{r}42.5 \\
\pm 6.57\end{array}$ & $\begin{array}{r}30.3 \\
\pm 4.83\end{array}$ \\
\hline Waves/AD Burst & 49.2 & \pm 4.8 & 55.3 & \pm 4.8 & $50.4 \pm 4.8$ & $49.6 \pm 4.9$ & $41.7 \pm$ & 36.6 & \pm 5.5 \\
\hline Wave Amplitude $(\mu \mathrm{V})$ & $3.7=$ & $\pm \quad .03$ & 3.8 & $\pm \quad .04$ & $3.4 \pm \quad .04$ & $3.4 \pm \quad .03$ & $3.2 \pm .03$ & 3.1 & \pm .03 \\
\hline Burst Duration (msec) & \multicolumn{2}{|c|}{$205.7 \pm 11.2$} & \multicolumn{2}{|c|}{$199.6 \pm 11.6$} & $202.0 \pm 12.9$ & $201.0 \pm 13.0$ & $194.5 \pm 11.7$ & \multicolumn{2}{|c|}{$194.0 \pm 11.8$} \\
\hline
\end{tabular}



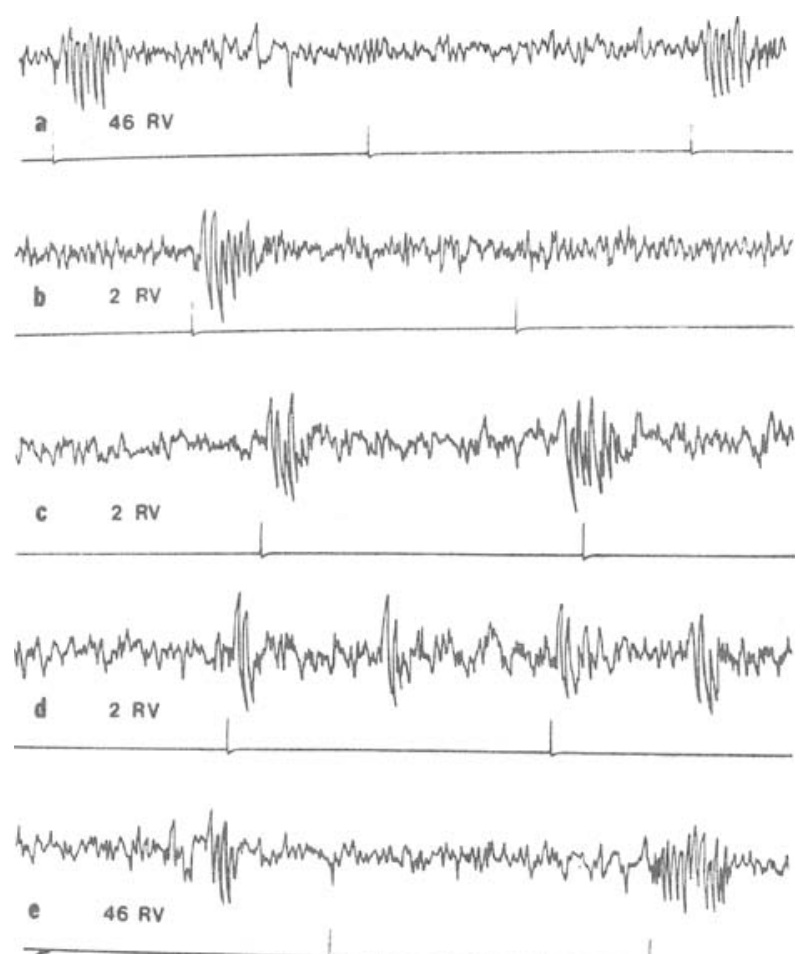

$$
50 u v \frac{\bigsqcup_{1 \mathrm{sec}}}{}
$$

Fig. 2. Illustrations of various patterns of afterdischarge (AD) and spontaneous AD-like bursts. An upward deflection of the horizontal line beneath each EEG inscription indicates the presentation of the photic pulse. The five differing EEG inscriptions represent the following for each photic stimulus presentation: (a) typical AD burst, no AD burst, typical AD burst in $S 46$; (b) typical $A D$ burst and no AD burst in S 2; (c) typical AD burst followed by AD bursting that has its initial spindling activity preceding the light flash; (d) typical AD bursts with AD-like activity interpolated between light flashes; and (e) AD-like burst that precedes the light flash, no AD, and a typical AD burst.

present study relative to the increase and decrease in AD elicitation. It is of particular interest that following an initial increase in AD bursting, which peaked during the second 5-min period of photic iteration, there was a successive decrease in bursting which reached its low point during the sixth sampling period. In the time interval between the peak level of AD bursting and the low point, the peak-to-peak amplitude of the largest wave in the burst complex did not differ. However, burst duration consistently declined over time, as did the number of waves per burst ( 0.93 rank-order correlation).

Prior research has repeatedly demonstrated that behavioral and/or EEG arousal blocks the development of AD (Fleming et al, 1972, 1973b; Fleming \& Bigler, in preparation; Rhodes \& Fleming, 1970). In the present investigation, it would appear that the 4-min delay in development of a consistent pattern of AD elicitation is related to a heightened arousal level initiated by the novelty of the photic stimulation. Evidence for this presumption was provided by Fleming et al (1972). They demonstrated that, with repeated experience with photic stimulation, AD bursting latency progressively shortened, i.e., as the rat became more familiar with the experimental situation, AD bursting was elicited more readily. In the present investigation, the elicitation percentage of $\mathrm{AD}$ bursting peaked during the second 10-min sampling period. Presumably, level of activation declined sufficiently to foster an increased probability of burst elicitation. However, following the second sampling period, the level of $\mathrm{AD}$ bursting progressively decreased. It would seem unreasonable to suggest that the decline in AD bursting would be subsequent to an increase in arousal level. On the contrary, with habituation it is apparent that there is a decrease in arousal level over time (Hinde, 1970; Thompson \& Spencer, 1966). If it can be assumed that there would be a relatively linear decrease in level of arousal as a function of time, then the possibility exists that there is an optimal level of arousal for the elicitation of $\mathrm{AD}$ bursts. Arousal levels above or below this optimal level would be associated with $\mathrm{AD}$ suppression to a greater or lesser degree.

Of particular interest is the observation that $\mathrm{AD}$ bursts and bursts of cortical spindles resembling AD bursts occurred at varying intervals before or after the delivery of a photic pulse. It may be that these bursts of discharges can be initiated or suppressed by the animal in a manner similar to that reported by Sterman, Wyrwicka, and Roth (1969) and may reflect a dimension of voluntary control over visual cortical rhythms. Much of the previous work has been concerned with the mechanisms of AD suppression (Fleming et al, 1972, 1973a, 1974; Fleming \& Bigler, in preparation, Rhodes \& Fleming, 1970; Shearer, Fleming, Bigler, \& Wilson, 1974). It would appear that the degree of operant behavioral control of occipital cortical discharges in the rat could receive profitable study.

\section{REFERENCES}

Draper, D. O., \& Venator, E. R. Chronic attachment of a connector to a rat's skull without screws. Physiology \& Behavior, 1972, 9, 113 .

Fleming, D. E., Rhodes, L. E., Wilson, C. E., \& Shearer, D. E. Time-drug modulations of photically evoked afterdischarge patterns. Physiology \& Behavior, 1972, 8, 1045-1049.

Fleming, D. E., Rhodes, L. E., Wilson, C. E., \& Shearer, D. E. Differential effects of convulsive drugs on photically evoked afterdischarge parameters. Psychopharmacologia, 1973a, 29, 77-84.

Fleming, D. E., Wilson, C. E., \& Shearer, D. E. Strain differences in the elicitation of electro-crotical afterdischarge. Physiology \& Behavior, $1973 \mathrm{~b}, 10,879-885$.

Fleming, D. W., Shearer, D. E., \& Creel, D. J. Effect of pharmacologically-induced arousal on the evoked potential in the unanesthetized rat. Pharmacology, Biochemistry, \& Behavior, 1974, 2, 187-192.

Hinde, R. A. Behavioral habituation. In G. Horn and R. A. Hinde (Eds.), Short-term changes in neural activity and behavior. Cambridge: Cambridge Press, 1970.

Rhodes, L. E., \& Fleming, D. E. Sensory restriction in the albino rat: Photically evoked afterdischarge correlates. Electroencephalography and Clinical Neurophysiology, 1970, 29, 488-495.

Shearer, D. E., Fleming, D. E., Bigler, E. D., \& Wilson, C. E. Suppression of photically evoked afterdischarge bursting following administration of anticonvulsants in waking rats. Pharmacology, Biochemistry, \& Behavior, 1974, in press.

Sterman, M. B., Wyrwicka, W., \& Roth, S. Electrophysiological correlates and neural substrates of alimentary behavior in the cat. Annals of the New York Academy of Sciences, 1969, 147, 723-739.

Thompson, R. F., \& Spencer, W. A. Habituation: A model phenomenon for the study of neuronal substrates of behavior. Psychological R eview, 1966, 73, 16-43.

(Received for publication July $5,1974$. ) 